\section{SARS-CoV-2 Superspread in Fitness Center, Hong Kong, China, March 2021}

\author{
Linsey C. Marr
}

Author affiliation: Virginia Polytechnic Institute and State University, Blacksburg, Virginia, USA

\section{DOI: https://doi.org/10.3201/eid2709.211177}

To the Editors: I read with interest the article by Chu et al. (1), which concluded that poor ventilation might have contributed to a severe acute respiratory syndrome coronavirus 2 (SARS-CoV-2) superspreading event at a fitness center in Hong Kong, China. As an example of SARS-CoV-2 not spreading in a converse environment, I report the absence of apparent transmission at a gym in Montgomery County, Virginia, USA, that emphasized ventilation as part of its coronavirus disease (COVID-19) precautions upon reopening in June 2020. The gym (Appendix Figure 1, https://wwwnc.cdc.gov/EID/article/27/9/211177-App1.pdf) increased ventilation by opening 10 exterior doors and keeping them open even during cold or inclement weather. The gym also limited class sizes, stressed hygiene, and required $\geq 10$ feet of distancing. Masks were not worn.

With the doors closed, the air change rate was estimated to be 0.07 air changes/hour, corresponding to a ventilation rate of $7.6 \mathrm{~L} /$ second/person $(\mathrm{L} / \mathrm{s} / \mathrm{p})$ on the basis of an occupancy of 10 persons, below the $10 \mathrm{~L} / \mathrm{s} / \mathrm{p}$ minimum recommended by ASHRAE (American Society of Heating and Air-Conditioning Engineers) for health clubs (2). With the doors open, these values were estimated to be 2.4 air changes/ hour and $240 \mathrm{~L} / \mathrm{s} / \mathrm{p}$ (Appendix).

On September 24, 2020, an instructor at the gym developed upper respiratory symptoms and lost his sense of smell and taste. He was tested for SARS-CoV-2 infection and received a positive result on September 28,2020 . That day, the gym owner contacted 50 persons who had attended $\geq 1$ of the instructor's classes during September 21-25, 2020 to notify them of potential exposure. During subsequent follow-up, none of these 50 persons reported any COVID-19 symptoms, and 5 people who got tested received negative results (Appendix Figure 2). It is likely that increasing ventilation greatly mitigated the risk of transmission (3). Subsequently, the gym acquired a $\mathrm{CO}_{2}$ sensor and kept the $\mathrm{CO}_{2}$ level, an indicator of respiratory emissions, well below 600 ppm (4) by adjusting the number of open doors.

\section{Acknowledgments}

Thanks to Kyle T. Bernstein, John T. Brooks, and Velvet Minnick for their assistance with this investigation.

This work was supported by the Virginia Tech Center for Emerging, Zoonotic, and Arthropod-borne Pathogens.

\section{References}

1. Chu DKW, Gu H, Chang LDJ, Cheuk SSY, Gurung S, Krishnan P, et al. SARS-CoV-2 superspread in fitness center, Hong Kong, China, March 2021. Emerg Infect Dis. 2021 May 18 [Epub ahead of print]. https:// doi.org/10.3201/ eid2708.210833

2. American Society of Heating, Refrigerating and Air-Conditioning Engineers. Ventilation for acceptable indoor air quality. ANSI/ASHRAE Standard 62.1-2019. 2019 [cited 2021 Jan 7]. https:// www.ashrae.org/technicalresources/bookstore/standards-62-1-62-2

3. Yang W, Marr LC. Dynamics of airborne influenza A viruses indoors and dependence on humidity. PLoS One. 2011;6:e21481. https://doi.org/10.1371/journal.pone.0021481

4. Peng Z, Jimenez JL. Exhaled $\mathrm{CO}_{2}$ as a COVID-19 infection risk proxy for different indoor environments and activities. Environ Sci Technol Lett. 2021;8:392-7. https:// doi.org/ 10.1021/acs.estlett.1c00183

\section{Address for correspondence: Linsey C. Marr, Civil and}

Environmental Engineering, Virginia Tech, 1145 Perry St, Durham 411, Blacksburg, VA 24061, USA; email: 1marr@vt.edu

\section{Fecal Excretion of Mycobacterium leprae, Burkina Faso}

\author{
Ajay Vir Singh, Rajbala Yadav, \\ Harpreet Singh Pawar, Devendra Singh Chauhan
}

Author affiliation: ICMR-National JALMA Institute for Leprosy and Other Mycobacterial Diseases, Agra, India

DOI: https://doi.org/10.3201/eid2709.211262

To the Editor: Millogo et al. (1) documented presence of Mycobacterium leprae in a fecal sample from a patient in Burkina Faso, raising questions about the role of fecal excretion of $M$. leprae in the natural history and diagnosis of leprosy. They speculated that $M$. leprae were swallowed by the patient along with blood 